I Universidade Estadual de Campinas (Unicamp),

Departamento de Sociologia, Campinas, SP, Brasil.

eliderugai@uol.com.br

Elide Rugai Bastos'

\title{
SOBRE OS PRINCÍPIOS: RICARDO BENZAQUEN E O PENSAMENTO SOCIAL'
}

Dedico este artigo a Carmen, tão importante em minha amizade com Ricardo.

Quando indagado sobre os principais objetos, a problemática e as abordagens teórico-metodológicas na área do pensamento social brasileiro, a propósito do simpósio organizado por Lilia Schwarcz e André Botelho para a revista Lua Nova em 20I I, Ricardo Benzaquen de Araújo respondeu:
A área atingiu um amadurecimento intelectual bastante significativo, tendo já mapeado, ao menos até certo ponto, parte dos mais importantes debates "socioló- gicos" do século XX. Ela também desenvolve, há tempos, um esforço no sentido de examinar, de forma mais sistemática o pensamento social do século XIX. Isso no que diz respeito aos temas. Quanto às abordagens, a velha oposição entre uma perspectiva que privilegia a análise interna dos textos e uma outra que procura explicá-los pelo destaque concedido ao contexto - em suas múltiplas dimensões - começa a conviver com posições que buscam combinar esses dois pontos de vista e portanto matizar aquela oposição (Botelho \& Schwarcz, 20 I I: I42).

Afirmar ser recente a tendência de matizar as oposições interpretativas faz parte da conhecida modéstia de Ricardo, que talvez não se reconhecesse como um dos pioneiros nesse movimento que levou a um avanço das abordagens na área do pensamento social entre nós. Esse matiz, representado pela combinação texto/contexto está presente desde os seus primeiros trabalhos sobre o integralismo e continuou a figurar nos estudos posteriores.

Buscando mostrar a consistente contribuição de Benzaquen à consolidação da área de pensamento social retomo o caminho trilhado por ele na defini- 
ção de um método de análise que enriquece o conjunto de instrumentos disponíveis à reflexão dessa área. Assinalo, ainda, que a construção desse caminho analítico começou bem antes da pesquisa e escritura de Guerra e paz, seu livro mais conhecido que definitivamente o consagrou como grande autor e teve sequência em trabalhos posteriores.

Ricardo desenvolve seus estudos sobre o integralismo no quadro da pesquisa Brasiliana no Centro de Pesquisa e Documentação de História Contemporânea do Brasil - CPDOC da Fundação Getulio Vargas, no Rio de Janeiro. Creio poder afirmar que se trata do primeiro e maior grupo organizado de investigação sobre o pensamento brasileiro, iniciado em I973. O passo inaugural desse projeto coletivo foi a realização de um levantamento bibliográfico referente à Revolução de I930 e sua análise (Oliveira, Gomes \& Whately, I980). Desdobrouse por meio do projeto Ideologia do Estado Novo e vários trabalhos sobre autores e correntes de ideias não mais restritos a esse período. A articulação entre pensamento e política sempre foi um objetivo presente na investigação, o que podemos constatar em diferentes trabalhos publicados pelos membros do grupo. ${ }^{2}$ Nesse quadro Ricardo publica os seguintes textos: "As classificações de Plínio: uma análise do pensamento de Plínio Salgado entre I932 e I938" (Araújo, I978); Totalitarismo e revolução: o integralismo de Plínio Salgado (Araújo, I988a); In medio virtus: uma análise da obra integralista de Miguel Reale (1988b).

O ponto de partida sobre o qual se assenta a pesquisa Brasiliana é em linhas gerais o mesmo utilizado por Bolivar Lamounier (I 977) ao estudar o pensamento autoritário dos anos I920, isto é, a fundamentação na categoria "estilos de pensamento" e a presença, para o conjunto de autores analisados, de "intenções básicas", posições analíticas tributárias a Mannheim (I959). Os trabalhos desenvolvidos no âmbito da pesquisa exploram aspectos diversos dessa formulação que basicamente se refere ao pensamento conservador. Lúcia Lippi Oliveira, acentuando a importância das categorias formulada por Mannheim, observa:

O estilo de pensamento, e suas intenções básicas instruídas a partir dos temas vinculados, está relacionado à posição do intelectual na sociedade em que vive e às possibilidades de influência em seu trabalho junto ao público. O êxito de um dado estilo, entretanto, nos remete para sua capacidade de ser eficaz, ou seja, de organizar uma argumentação ideológica e intelectual capaz de atender às demandas de seu tempo (Oliveira, Gomes \& Whately, I980: 35).

A perspectiva desenvolvida por Benzaquen dá conta desse princípio analítico. Primeiramente localiza os autores e seus escritos durante o período da Ação Integralista Brasileira, compreendido entre I932 e I938, a partir de sua diferenciada formação e de seu itinerário profissional e intelectual. Às posições diversas acrescenta que, apesar de pontos de vista comuns, cabe identificar estilos de pensamento diferentes assumidos por eles: totalitarismo e conservadorismo. A demonstração dessa questão é feita por Benzaquen empregando o procedimento denominado por Mannheim busca da "nomenclatura do pensa- 
mento", que ele aborda com base na articulação entre as categorias presentes nos discursos dos autores. Ainda, como discutiremos no decorrer deste artigo, ao privilegiar o arranjo conceitual interno aos textos de Plínio Salgado, pode mostrar a vizinhança e o distanciamento desse autor daqueles intelectuais e políticos classificados por Lamounier (I977) como conservadores.

\section{DERIVAÇÃO DAS CATEGORIAS}

No estudo sobre o integralismo, Benzaquen busca apreender a lógica do pensamento de Plínio Salgado partindo da derivação entre as diversas categorias utilizadas por este autor, concebidas como instrumentos de pensamento. ${ }^{3}$ São, portanto, as concepções básicas usadas pelo fundador da Ação Integralista Brasileira que conferem sentido às expressões utilizadas. Em outros termos, elas não podem ser analisadas de forma independente do projeto político proposto, pois, apesar de coincidirem com outras categorias empregadas em textos nacionais ou estrangeiros, apresentam-se, no conjunto, com significado diverso, porque originárias de outro contexto histórico e de outro contexto léxico, este derivado das chaves históricas que as organizam. "A análise de caráter sistemático torna extremamente difícil a compreensão do sentido específico das categorias, o qual só pode ser captado através do entendimento das relações internas do pensamento integralista" (Araújo, I978: I62).

Assim, marca a diferença entre a abordagem que elegeu para analisar a Ação Integralista Brasileira e alguns textos anteriores sobre o mesmo tema. ${ }^{4}$

A menção a Durkheim diz muito sobre o caminho trilhado por Benzaquen. Lembro que Raymond Aron (I967) afirma ser parte de As formas elementares da vida religiosa uma introdução à sociologia do conhecimento. De fato, a primeira parte desse livro indica no subtítulo a realização de pesquisa religiosa e teoria do conhecimento. A abordagem do pensamento de Plínio Salgado por Benzaquen se faz levando em conta que "as categorias do pensamento humano jamais são fixadas de uma forma definitiva; elas se fazem e desfazem, se refazem permanentemente; mudam conforme os lugares e as épocas" (Durkheim, I996: XXII). Mostrando que a teoria sociológica constitui-se no modo de superação das teses que consideram as categorias ou como a priori do conhecimento ou como resultantes do empirismo, procura encontrar a síntese dos opostos na forma de intervenção da sociedade. Assim, afirma o sociólogo clássico:

Se as categorias são, como pensamos, representações essencialmente coletivas, elas traduzem antes de tudo, estados da coletividade. [...] Aparecem, então, não mais como noções muito simples que qualquer um é capaz de extrair de suas observações pessoais [...] mas, ao contrário, como hábeis instrumentos de pensamento (Durkheim, I996: XXIII-XXVII).

A associação ideia/história está explícita nessa passagem. Em conformidade com essa mesma posição a pesquisa de Benzaquen dialoga criticamente com estudos anteriores que, por apresentar as categorias deslocadas do con- 
texto em que são produzidas, podem analisá-las como dotadas de significado autônomo, de modo a permitir "a comparação dos autores integralistas com outras formas de pensamento, tanto na Europa como no Brasil, que também usam as mesmas categorias" (Araújo, I978: I62). Confrontando essa visão homogeneizadora, mostra que há encaminhamentos diferentes no seio do próprio grupo que compõe a Ação Integralista Brasileira - o que melhor se observa no estudo sobre Miguel Reale, escrito em I983 e publicado em I988. O ponto de partida analítico é a constatação de ser o integralismo prioritariamente uma doutrina que visa à ação e à mobilização sócio-político-cultural. Portanto, a afirmação de ser o integralismo não só um conjunto de ideias, mas principalmente um movimento político está contida no contexto brasileiro do período compreendido entre i932 e i938.

Ricardo Benzaquen aponta os diversos passos de sua pesquisa, que resultaram em textos elaborados em momentos diferentes, e tal caminho o leva a apurar a visão sobre o movimento e os autores em foco, o que se inicia pela escolha do próprio objeto da análise. Se o cenário eleito para a pesquisa conjunta - o projeto Brasiliana - define o período do estudo, a escolha do integralismo como alvo da investigação não se explica somente por esse enquadramento. De um lado, considera "que a revolução de 30 deva ser encarada como uma peçachave para a compreensão do surgimento e da expansão do integralismo a partir de I932" (Araújo, I988a: p. 25). O clima de indefinição e imprevisibilidade políticas do período provoca o aparecimento de novas propostas. De outro lado, embora Plínio Salgado não possa ser considerado um dos autores mais importantes dessa década, é muito grande a repercussão de suas ideias e ações, resultando no fato de a Ação Integralista Brasileira se tornar o primeiro partido nacional de massa. ${ }^{5}$ Desse ponto de vista, podemos deduzir que Benzaquen considera a crise não só quadro que abriga uma revisão das normas de organização da sociedade, mas cenário que comporta um novo sentido heurístico, isto é, que predispõe ao surgimento de novas categorias analíticas. O estudo desse sentido heurístico será também um dos eixos da construção do livro Guerra e paz: Casagrande \& senzala e a obra de Gilberto Freyre nos anos 30 (Araújo, I994).

Assim, do ponto de vista metodológico, seu primeiro movimento foi colocar-se na posição de reconhecer que o pensamento de Plínio Salgado "em vez de ser composto por um amontoado de postulados irracionais, possuía uma lógica particular, muito próxima do rico e complexo conservadorismo europeu" (Araújo, I988a: I9). Recusa, portanto, a visão naturalizada, difundida por certa bibliografia, na análise desse autor. O mesmo procedimento aparece na definição do diálogo que faz com alguns analistas da obra de Gilberto Freyre, tema que abordarei mais adiante. O segundo passo foi apontar o afastamento desse autor do conservadorismo, corrente de pensamento voltada para a crítica do liberalismo, visão com a qual Plínio Salgado concorda. Porém, embora ressalte essa posição, insiste "numa completa transformação da vida social no Brasil e 
no mundo, num corte absoluto com todas as tradições anteriores" (Araújo, I988a: I9-20) Em outros termos, Benzaquen passa a considerar central a noção de espírito revolucionário mobilizando as ideias do autor estudado. Uma terceira perspectiva, consequência das duas anteriores, leva-o a questionar se seria apropriado analisar o integralismo de Plínio Salgado "a partir de sua vinculação à ideologia conservadora" (20). Lança mão, assim, do conceito de totalitarismo, o que define a presença de outro estilo de pensamento, que o diferencia do tradicional conservadorismo europeu.

O caminho percorrido permite ressaltar dois elementos constitutivos da visão de integralismo em Plínio Salgado e sua posição intelectual no quadro da Ação Integralista Brasileira, marcados pelo totalitarismo: primeiro, uma concepção absolutizada da ideia de participação e, segundo, a identificação com noções de igualdade e uniformidade. Resulta disso o afastamento na análise das concepções de conflito e de diferença, o que estabelece a visão crítica ao liberalismo diversa não só do pensamento autoritário de origem conservadora, como do marxismo. ${ }^{6}$ Prevalece a noção da existência de interesses gerais e o não reconhecimento de interesses conflitantes entre os grupos componentes da sociedade.

Chamo a atenção para a lição contida nessa formulação de Benzaquen sobre como se edifica uma investigação. Ele, que era avesso a propor lições, negando-se a ser professoral, ao sugerir a liberdade de pensamento como fundamento do trabalho intelectual, acaba por mostrar que na área de pensamento social as hipóteses são construídas no próprio decorrer da pesquisa; mais ainda, que nesse processo não sabemos exatamente aonde vamos chegar. Assim, a beleza do trabalho intelectual está sempre na descoberta, possibilidade aberta para toda pesquisa que não parta de soluções predefinidas. Com a clareza que demonstra sobre os caminhos do conhecimento, Ricardo aponta os limites dos passos empreendidos e, assim, o caráter incompleto de seus próprios es forços analíticos. Nessa direção, tanto no sentido proposto por Horácio como por Kant, arrisca-se sempre a "ousar saber", atitude fundamental para o avanço do conhecimento.?

\section{INTENÇÕES BÁSICAS}

Admitidas as diferenças em relação ao arranjo interno das categorias e dos temas nos vários autores - o que permite percebê-los como um conjunto, além do fato de pertencerem ao mesmo movimento, a Ação Integralista Brasileira -, Ricardo Benzaquen identifica uma intenção básica comum a todos, que tem por fundamento um conjunto de ideias formuladas num contexto em que as mudanças sociais e políticas abrem espaço para essa formulação.

O integralismo foi um movimento que surgiu por volta de I932, no tumultuado e incerto contexto que se seguiu à Revolução de 30 , trazendo como novidade essencialmente dois elementos: a proposta de se organizar nacionalmente, contra uma tradi- 
ção que baseava e confinava a vida política brasileira dentro dos limites do "coronelismo" e das alianças locais, e a preocupação em orientar a sua atividade a partir de uma doutrina, opondo-se ao costume, tão comum na República Velha, de misturar "clientelisticamente" as relações pessoais com as de poder (Araújo, I988b: I).

As intenções básicas comuns no seio do movimento, as quais no itinerário dos diferentes autores se traduzem em concepções diversas, direcionamse a um projeto de reorganização da sociedade nacional que se opõe aos esquemas políticos anteriores. Esse projeto comportava a retomada dos princípios espiritualistas afastados pelas formas de organização sócio-político-culturais que se fundam no materialismo - o capitalismo liberal e o comunismo - e se estenderia ao conjunto da sociedade. Assim, na visão de Benzaquen, o projeto propunha não apenas a construção de uma sociedade homogênea, sem diferenças sociais que resultassem em desigualdades, mas também a implementação de uma mobilização político-social permanente e ampla, que transformasse todos os cidadãos em militantes, como via privilegiada para se atingir e sustentar essa sociedade.

Prefaciando o livro Totalitarismo e revolução, Francisco Falcon (I988a: I I) assinala a importância desse estudo na compreensão geral do período de constituição e desenvolvimento da Ação Integralista Brasileira, contribuindo "para que se tenha uma visão mais matizada do clima mental então reinante", ao ressaltar a localização desse movimento político e das ideias correspondentes no contexto histórico, de modo a apreender o papel desempenhado naquele cenário tanto por seu líder como pelos militantes que o constituíram.

Além da análise do conteúdo dos textos elaborados nessa conjuntura histórica, os autores compartilham ponto de vista comum em relação à crise "em que o mundo se debatia, o lugar do Brasil nessa crise, e a proposta de restauração e soerguimento trazidos pelo integralismo" (Araújo, I978: I63) -, Benzaquen lembra outro aspecto do contexto que funda diferenças entre os diversos autores importantes no movimento. Assim, afirma não ser possível reduzir toda a riqueza e complexidade da doutrina da Ação Integralista Brasileira a perspectiva única. Assinala que, como em qualquer outro movimento político, reconhece-se a existência de diferentes linhas ideológicas, provenientes de origens diversas a partir de contextos léxicos de formação teórica ampliada. Por isso, além de examinar o pensamento do fundador, aponta a especificidade da interpretação de Gustavo Barroso, chefe da milícia do integralismo, e se debruça sobre o exame do período integralista na obra de Miguel Reale. No exame das proposições dos três autores mostra que os dois primeiros,

embora por caminhos inteiramente diferentes, ambos se aproximavam de uma perspectiva totalitária. [Diferentemente], o estudo dos textos de Reale deixa claro que ele adotava um ponto de vista eminentemente conservador, em que a preocupação com o conjunto, com o todo, não implica a abolição, a anulação das partes que o compõem (Araújo, I988b: 3). 
A diferença entre as propostas tem por base não só o contexto histórico da formação dos autores, mas o contexto léxico em que se fundamentam. ${ }^{8}$ Plínio Salgado e Gustavo Barroso se instruíram e se aperfeiçoaram dentro do "mundo" intelectual da Primeira República, destacando-se como jornalistas e/ou literatos, enquanto Reale ingressou no integralismo depois de ter concluído a faculdade de direito na Universidade de São Paulo. Se a questão social já era sua preocupação anterior, esse curso permitiu-lhe desenvolver o talento para as leis que definiria seu perfil como jurista, o que marcou sua atividade política. A formação acadêmica levou-o a encaminhar a preocupação com a questão social "dando-lhe um sentido extremamente moderado e erudito, erudição que se apoia, antes de mais nada, em autores vinculados à chamada tradição sociológica, como Durkheim, Tocqueville e Burckhardt" (Araújo, I988b: 5)..$^{9}$ E, invocando Nisbet (I966), Benzaquen (Araújo, I988b: 5, nota 6) lembra que esses autores "estabeleceram uma relação, mesmo que complexa e diferenciada, com a perspectiva conservadora". Tal posição explicaria o fato de Reale vir a ocupar a chefia do Departamento Nacional de Doutrina da Ação Integralista Brasileira.

Trata-se, como podemos ver, de uma metodologia que integra pensamento e contexto, apontando dupla condição de análise: permite perceber de um lado a importância de definição do lugar da enunciação das ideias - espaço e tempo - e de outro a articulação de sentido entre as formulações e não apenas o significado autônomo dos conceitos. É a partir dessa dupla perspectiva que Benzaquen afirma configurar-se o pensamento de Plínio Salgado como doutrina e não como teoria.

\section{CHAVES DA HISTÓRIA}

O desenvolvimento da temática do totalitarismo remete à influência de Hannah Arendt na reflexão de Ricardo Benzaquen, que utiliza a expressão "chaves da história" no mesmo sentido apontado por essa autora. ${ }^{\text {10 }}$ Mostra que Plínio Salgado opera com o que afirma ser as categorias básicas do integralismo - o materialismo e o espiritualismo - como "chaves da história", que fundamentam todo o esquema intelectual por ele desenvolvido. O líder integralista considera que "elas nomeiam dois planos essenciais e antagônicos da existência humana, planos que sempre estiveram presentes, em todos os lugares e desde o princípio dos tempos, sempre na mais aguda oposição" (Araújo, I988a: 29). A forma pela qual esses elementos se combinam concretizando-se na história teria originado civilizações completamente diferentes. Assim, essa visão produz uma espécie de congelamento da história em torno de duas concepções perenes.

Embora as ideias de Plínio Salgado estejam dispersas em toda a sua obra, dois livros - O que é o integralismo (I933) e Psicologia da revolução (I935) - são mais profundamente analisados por Benzaquen, que os considera os mais sintéticos de todo o conjunto, embora recorra, para ampliar esclarecimentos, a outros publicados em momentos diversos. O objetivo dos dois textos é o mesmo: a exposição sistemática e condensada do pensamento do fundador da Ação 
Integralista Brasileira. Eles, no entanto, visam a públicos diferentes. O primeiro dedica-se à massa popular; ao "brasileiro modesto que trabalha e sofre" (Salgado, I933: I9 apud Araújo, I 988a: 28). O segundo destina-se àqueles que "pretendem influir nos destinos do povo [...] aos políticos e intelectuais" (Salgado, I935, prefácio apud Araújo, I988a: 28). Sendo este de construção mais aprofundada e sofisticada, apresenta "a análise mais cuidadosa e elaborada das duas categorias básicas da doutrina integralista de Plínio, o materialismo e o espiritualismo" (Araújo, I988a: 28).

As duas concepções balizam a compreensão e atravessam toda a história da humanidade, lutando sempre entre si, com a prevalência de uma ou outra e mesmo com a fusão de ambas, em diferentes períodos. "A relação entre esses dois conceitos, a maneira pela qual eles se articulam, se revezam, se antepõem, ou se conciliam, para de novo se separar, vai dar sentido, para Plínio, a toda a história da humanidade (Araújo, I978: I64).

$\mathrm{Na}$ classificação feita pelo líder integralista, a terceira fase do desenvolvimento da humanidade, que se iniciaria no século XIX e seria marcada pelo materialismo, confere sentido à civilização burguesa, capitalista. Tendo como traço intrínseco o ateísmo, abandona os fundamentos em valores espirituais e, portanto, será destituída de moral. Reforça-se, assim, conforme aponta Benzaquen, o caráter doutrinário do integralismo. Os indivíduos deixam de ter motivos morais para ser solidários, e a competição passa a ser a regra que ancora os relacionamentos, sendo o objetivo último da ação a obtenção de riqueza. O trabalho perde sua finalidade superior, não mais mediado pelas exigências do espírito, e volta-se apenas para o dinheiro e o lucro. Assim, o tradicional sentido da propriedade, que a caracterizava como uma relação íntima e pessoal garantindo a família, sendo o suporte material do indivíduo e o elo pelo qual as gerações sempre estiveram ligadas -, também é destruído. Ela se converte em bem móvel, transferindo-se das mãos do "operário, do pequeno artífice, do lavrador ou comerciante" para o controle do capital (Araújo, I978: 167).

Os conceitos de "homem cívico" e de "soberania nacional", esta vista como soma das vontades dos homens cívicos, organizam a política na civilização liberal. Essa relação se configura por meio do sufrágio universal. Benzaquen mostra que a crítica de Plínio Salgado ao liberalismo - considerado sistema político absurdo - direciona-se principalmente a seu fundamento em concepções abstratas. ${ }^{\text {II }}$ Sem discutir propriamente as alternativas conceituais, volta-se ao efeito político dessas noções: a forma delas derivada de representação política, o sufrágio universal.

Para ele, a única representação efetiva é aquela que leva em consideração os interesses concretos e específicos dos grupos básicos da nação - as famílias e as classes profissionais. Ora, na democracia liberal os únicos interesses representados são os gerais, abstratos, do "homem cívico", uma figura falsa, artificial, construída pela filosofia liberal (Araújo, I978: I67). 
Desse conjunto de argumentos Plínio Salgado deduz a consequente ruptura entre o Estado liberal e a sociedade. ${ }^{12}$ Se isso é um dado básico, como analisa a situação do Brasil nesse quadro? Sendo um capítulo da expansão mercantil europeia, o país nasce em meio a um processo que visa à riqueza da metrópole, e a ocupação do território realiza-se com esse objetivo. "O Brasil nasce do 'fato', não da 'ideia' liberal" (Araújo, I978: I69). No entanto, o isolamento das populações, principalmente no período colonial promove a produção de uma cultura autenticamente brasileira ancorada em valores diferentes daqueles prevalecentes na civilização europeia.

O período colonial é visto pelo líder integralista como um momento de criação desses valores. Primeiramente pelo fato de o encontro dos portugueses com os indígenas ter-se dado em clima de harmonia e cooperação. Essa relação seria resultado da articulação entre o espiritualismo presente no politeísmo comum aos índios das Américas e "as ideias nítidas do espiritualismo cristão que nos trouxeram os jesuítas" (Salgado, I934: 70 apud Araújo, I988a: 52). Em segundo lugar, pela "irmanização" das três raças, processo resultante das dificuldades climáticas e de relevo do Brasil, que aplainava diferenças e oposições. Mesmo a escravidão africana não teria sido obstáculo a essa harmonização dos interesses, pois foi marcada pela intimidade e confiança entre senhores e escravos. Construiu-se assim, "segundo Plínio, uma 'democracia bárbara' e 'selvagem', peculiarmente brasileira, na qual, apesar das diferenças iniciais, todos conseguem viver na mais absoluta igualdade de condições" (Araújo, I988a: 53). O espírito igualitário vigente no período colonial se expressa bem, segundo o líder integralista, "na impressionante democracia racial que aqui vigorava, acarretando uma inédita fusão entre os três grupos, índios, negros e brancos, que davam início, então, ao povoamento do país" (54). O caboclo, produto dessa fusão racial, é, então, o portador do espiritualismo que permitiu essa igualdade racial e social.

A partir da ocupação do litoral, que se dá nas diversas regiões brasileiras em diferentes momentos, há uma ruptura, e esses valores tradicionais persistem apenas no interior do país. "É como se a ausência da 'ideia' liberal tivesse aberto um espaço, logo ocupado pelos valores espirituais brasileiros" (Araújo, I 988a: I70). Disso resulta que o país "não pode ser pensado como uma unidade, pois existem pelo menos dois Brasis, irredutíveis e antagônicos: o Brasil 'real' [do interior, do sertão, do setor rural], e o Brasil 'formal', 'civilizado', que fica no litoral" (I69). Com base nesse diagnóstico, Plínio Salgado deduz que o Estado liberal nada tem a ver com a sociedade, pois desconhece os conflitos existentes e é fraco, anêmico e gelatinoso. As elites alocadas no litoral são dominadas pelos interesses privados, indiferentes às necessidades nacionais.

Essa elite cosmopolita, fascinada pelas últimas modas de Paris, vai desconhecer inteiramente o Brasil "real", do interior, acreditando nada ter a ver e a partilhar com ele. Sem se interessar por qualquer coisa que aconteça fora do litoral, ela jamais vai ver o Brasil como uma unidade, como uma nação (Araújo, I978: I7I). 
O diagnóstico, ancorado nas chaves históricas interpretativas de Plínio Salgado, impõe a necessidade iminente de uma revolução que "terá sempre um sentido ético, moral, implicando 'interferência' do conceito espiritualista de vida sobre a concepção materialista" (Araújo, I978: I72). A revolução integralista seria realizada por um pequeno grupo de homens que transmitiriam ao conjunto da população a verdadeira ideia de revolução, transformando-se em mediadores entre o espírito e o mundo, portando o lema "Deus, Pátria e Família”, representando valores que reestabeleceriam o domínio da ordem na sociedade brasileira.

O objetivo do movimento integralista, operando como instrumento do espírito, seria a substituição do Estado liberal - fundado em interesses abstratos - pelo Estado integralista, apoiado em outra organização social, o corporativismo, que tem por base interesses concretos de grupos - as classes profissionais. A nova configuração comportaria uma alteração na forma de representação política, e não mais no sufrágio universal. As classes profissionais elegeriam seus representantes nas câmaras municipais, nos congressos provinciais e no congresso geral. Trata-se de representação hierarquizada; as câmaras municipais indicariam os prefeitos; os congressos provinciais, os governadores; o congresso geral, o chefe da nação.

Os vários elementos elencados na leitura que Benzaquen faz do integralismo via os escritos de Plínio Salgado permitem-lhe interpretá-lo a partir do conceito totalitarismo.

Assim, a confusão entre igualdade e indiferenciação, como vimos na discussão da versão de Plínio do "mito das três raças", aliada à decisão de superar a questão social criada pelo materialismo [em relação ao trabalho e à propriedade] através da ênfase numa mobilização absoluta da população, eliminando-se qualquer pluralismo político e social, são sinais evidentes da relevância desse conceito para minha análise (Araújo, I 988a: 78).

Nessa exposição Benzaquen acrescenta um elemento importante para completar a metodologia que serve de base a sua análise: a necessidade de um suporte teórico. Lembro que em seus textos a exposição dos princípios explicativos que fundam a Ação Integralista Brasileira antecede sua interpretação, que a filia a uma corrente totalitária e não propriamente conservadora. Mais uma vez ressalto a preocupação de explicitar os passos em sua pesquisa. Mostro em suas próprias palavras o procedimento para melhor esclarecer seu lugar no estudo do pensamento brasileiro. Trata-se da tomada de uma posição que põe em questão algumas interpretações sobre essa área de estudos que a consideram uma abordagem "menor" no quadro das ciências sociais, identificando muitas vezes o estudo de autores brasileiros do passado como ultrapassado, uma espécie de arqueologia sem interesse atual. Benzaquen mostra que sua apresentação do integralismo 
esteve marcada, desde o início, por uma série de trabalhos que levantam e discutem a questão do totalitarismo, em particular os de Hannah Arendt (I979), Raymond Aron (1965), Claude Lefort (I98I) e Isaiah Berlin (I975), leitura ampliada e matizada pela consulta a estudos históricos. [...] Minha intenção não foi, portanto, a de levantar os "fatos" para depois elucidá-los à luz de conceitos (Araújo, i988a: 77).

\section{GUERRA E PAZ}

Publicado em 1994, Guerra e paz: Casa-grande \& senzala e a obra de Gilberto Freyre nos anos 30 retoma, sob outro ângulo, a metodologia empregada na análise da obra de Plínio Salgado. Pesquisa acurada, extrema competência na percepção do desenrolar e das minúcias da narrativa, elegância da escritura são algumas das qualidades, entre muitas outras, que embasam o texto. O livro não se entrega facilmente ao leitor que busca encontrar linearidade na explicação sobre Gilberto Freyre e sua concepção da sociedade brasileira. Benzaquen reconstrói o caminho de vai e vem na procura da explicação desse autor sobre a singularidade do país. Demonstrando tratar-se de visão híbrida, e mesmo ambígua, elege passagens importantes da obra que carregam duplo sentido, sentidos muitas vezes contraditórios. Exemplo esclarecedor se encontra no início do primeiro capítulo, em que transcreve frases de Casa-grande \& senzala em que Gilberto refere seu encontro, em Nova York, com marinheiros brasileiros, "mulatos e cafusos" que lhe deram a "impressão de caricaturas de homens", mostrando que "a miscigenação resultava naquilo" (Freyre, I933: XII apud Araújo, I994: 27). Lê esse parágrafo sugerindo que se trata do modo como Gilberto introduz "no texto a questão da raça de forma peculiarmente dramática, visto que a expõe através de uma confissão de racismo para, no mesmo momento distanciar-se decisivamente dela" (Araújo, I994: 27) O distanciamento se dá com o reconhecimento da influência de Boas, que o teria levado a perceber a diferença entre raça e cultura.

A abordagem eleita por Benzaquen constitui-se em escolha metodológica que preside a narrativa, permitindo abrir espaço para várias indagações a que submete os textos analisados e conduzindo o leitor a seguir os passos de sua pesquisa. Embora o modo de proceder seja semelhante àquele usado nos estudos anteriores, neste ganha outra feição. Creio poder aproximar esse método ao de "efeito de estranhamento" desenvolvido por Brecht, pois na análise recusa em princípio qualquer visão naturalizada das posições expressas por Freyre, seja as que o acusam de interpretação idílica sobre a sociedade colonial, seja aquelas que afirmam sua persistência em ponto de vista biologizante. Sempre em perspectiva respeitosa em relação a interpretações diferentes das suas, Benzaquen oferece outra possibilidade de leitura. Exemplifico: sobre a acusação de imprecisão de Freyre na questão da raça, presente em parte da bibliografia, argumenta:

Mas será que este diagnóstico de indefinição e falta de rigor encerra definitivamente o debate sobre o papel desempenhado pela noção de raça em CGS? Não cultivo, obviamente, nenhuma desconfiança quanto à veracidade e ao peso dos argumentos 
apresentados, mas tenho a impressão de que valeria a pena um rápido esforço para tentar qualificá-los e levá-los um pouco mais adiante (Araújo, I994: 33).

Assim, parte para uma revisão bibliográfica sobre a noção de raça, assinalando seus diversos significados, para visualizar e comparar o modo de operar de Gilberto Freyre em relação a essas concepções.

Emprego o termo estranhamento indicando uma atitude de desconforto, de distância diante do conhecido que se define como única interpretação verdadeira. E se afirmo tratar-se de um ponto de partida metodológico, vejo-o como um método dentro de um método, isto é, o método de Gilberto é incorporado e refinado por Benzaquen. Ilustro com a questão da raça, mas creio que o procedimento se estende a vários elementos abordados. A partir do curioso texto do prefácio de Casa-grande \& senzala, exposto acima, Benzaquen mostra que o autor "opera com o conceito de raça, mas transmite a curiosa sensação de que não quer se comprometer com o seu sentido mais usual, deixando-nos diante de um dilema ou, pelo menos, obrigando a questão a permanecer em aberto" (Araújo, I994: 38).

Não comprometimento porque Gilberto introduz um elemento de grande importância na costura das teses apresentadas: o meio físico, compreendido como noção "intermediária entre os conceitos de raça e cultura, relativizando-os, modificando seu sentido mais frequente e tornando-os relativamente compatíveis entre si" (Araújo, I 994: 39). ${ }^{\text {I3 }}$ O caminho eleito permite que as visões às vezes antagônicas presentes nesse livro não sejam interpretadas necessariamente como ambíguas, não resolvidas por meio de sínteses ou dissolvidas numa terceira posição, mas operadas como acomodações fundamentais para o desenvolvimento da narrativa. Sugere caber ao leitor a escolha.

A démarche leva a uma narrativa marcada pela oralidade, tema que já foi bastante analisado em estudos sobre Gilberto Freyre. Se, porém, nesse autor a oralidade paulatinamente assume característica de convencimento, ${ }^{\mathrm{I} 4} \mathrm{em}$ Benzaquen o sentido e o efeito da adoção dessa linguagem são diferentes, ganhando sofisticação, pois afirma sua posição, mas deixa espaço para que o leitor possa decidir se seus argumentos têm sustentação. Se, como afirmei, trata-se da forma de operacionalização do método, vale lembrar que a atitude faz parte, também, da modéstia e da generosidade que sempre marcaram a personalidade de Ricardo. São traços que aparecem em suas aulas, conferências, orientações e conversas com amigos. Lembro-me sempre de expressão que pontuava suas falas - "vejam bem" - com a intenção de dizer: minha visão é essa, mas vocês podem discordar; eu não a imponho como única possível.

\section{CONTEXTO HISTÓRICO E CONTEXTO LÉXICO}

A afirmação sobre a importância de referência aos contextos léxico e histórico, bem demarcada nos textos sobre o integralismo, em Guerra e paz está dispersa ao longo do livro, resultado do processo de argumentação aqui indicado, que 
prima pela não linearidade. A intenção, contudo, está expressa na introdução, em que Benzaquen explicita por que se dedica a estudar a obra de Freyre dos anos I930. "A questão que fez com que eu seguisse esse caminho diz respeito, acima de tudo, ao meu interesse em examinar as relações que podem ser estabelecidas entre as ciências sociais, amplamente definidas, e as propostas modernistas, ainda influentes no período" (Araújo, I994: I9).

Lembra que esse autor se dizia modernista e se relacionava proximamente com escritores como Manuel Bandeira, Prudente de Morais Neto, Rodrigo Melo Franco de Andrade, entre outros. Mas recorda, também, que certa crítica o coloca em posição inversa, considerando que sua obra se contrapõe às tendências modernizantes "pelo regionalismo e pelo perfil tradicional, aristocrático e conservador que a caracteriza" (Araújo, I994: 2I).

Colocando-se de forma diferenciada em relação a essa interpretação, sugere posicionar Gilberto num "outro modernismo, eventualmente distinto daquela postura a um só tempo modernista e modernizadora que se tornava gradualmente hegemônica entre nós" (Araújo, I994: 2I). Sem enfrentar diretamente a questão formulada - isto é, a relação entre as ciências sociais e aquelas propostas -, aponta autores de outra vertente modernista que constroem "uma imagem da sociedade marcada por um grau inusitado de tensão e ambiguidade" (22). Assinalo que esses são temas centrais de toda a sociologia que se dedica a analisar a mudança social, sem dúvida eixo da preocupação de Freyre. ${ }^{15}$

Dedicando-se a explorar uma das vertentes dessa relação Benzaquen (Araújo, I994: 23) opta "por uma abordagem enfaticamente monográfica da reflexão de Gilberto, alternativa que torna possível uma análise mais aprofundada, mais atenta às ambiguidades e paradoxos do seu pensamento". O procedimento deixa abertas hipóteses fecundas para a pesquisa daquela relação diante do modo pelo qual apresenta os diversos ângulos da transgressão, do excesso, da collage, em contraposição à ordem e ao equilíbrio que compõem os antagonismos presentes na sociedade brasileira, conforme expostos por Freyre. Inegavelmente, a sugestão daquela aproximação tem fundamentos muito bem desenvolvidos ao longo de Guerra e paz. Não cabendo aqui fazer minuciosa exposição desse desenvolvimento, passo a indicar apenas alguns pontos sem ter a pretensão de esgotar a questão.

Já apontei, quando me referi a raça, o cuidado de Benzaquen para definir o sentido de cada categoria analítica empregada pelo autor para demonstrar as nuanças de sua interpretação. Esse mesmo cuidado ele mantém no desenrolar da análise. Mostra que Freyre busca "um entendimento mais complexo e nuançado da noção de mestiçagem [...] não aplicada somente ao fruto do intercâmbio entre as diversas raças que povoaram o Brasil" (Araújo, I994: 43) Indica que em Casa-grande \& senzala o português antes de sua chegada a este país "perde inapelavelmente a sua identidade de branco 'puro', passando então 
a ser encarado como personagem híbrido" (43). Assim, a definição do povo luso, somando elementos de ordem geográfica - considerando Portugal situado entre Europa e África - com os cruzamentos étnicos e culturais decorrentes dessa situação, permite que a combinação dos elementos raça, cultura e clima, presentes na visão neolamarckiana, ganhe concretude. Em outros termos, a concepção de mestiçagem envolve a definição "do mestiço como alguém que guarda a indelével lembrança das diferenças presentes na sua gestação" (44). Esse conceito de mestiçagem estende-se à população brasileira.

Não se trata de preciosismo conceitual, mas de uma questão central, pois a afirmação fundamenta a tese dos antagonismos em equilíbrio que caracterizaria a sociedade brasileira e atravessa a exposição de Casa-grande \& senzala.

O hibridismo, marca do português e, por consequência, do brasileiro, permite que Gilberto o defina “em função de um 'luxo de antagonismos', que, embora equilibrados, recusam-se terminantemente a se desfazer e a se reunir em uma entidade separada, original e indivisível" (Araújo, I994: 44). Essa seria a razão da não presença nessa população tanto de um só tipo biológico como de forte constituição espiritual. "Diferença, hibridismo, ambiguidade e indefinição: parecem ser estas as principais consequências da ideia de miscigenação utilizada em CGS" (46).

Tal caráter explica os traços de "mobilidade, miscibilidade e aclimatibilidade" presentes na população portuguesa. Esses elementos compõem a "plasticidade" que Freyre lhe confere.

Nesse caminho, Benzaquen aos poucos mostra, incluindo vários passos na argumentação, a heterogeneidade da colonização portuguesa. No cenário da escravidão, sem dúvida marcada pela desigualdade das relações, "a violência e a proximidade sexual, o despotismo e a confraternização familiar parecem também ter condições de conviver lado a lado, em um amálgama tenso, mas equilibrado" (Araújo, I994: 57).

A direção é aplicada à noção de excesso, que impregna "o conjunto social da casa-grande, convertendo-se em uma das categorias mais importantes para a sua adequada compreensão" (Araújo, I 994: 59) Partindo do "trópico" que funda a ideia de desequilíbrio - "tudo aqui era desequilíbrio. Grandes excessos e grandes deficiências as da nova terra" (58) - a amplia para explicitar o excesso sexual e o âmbito de convivência:

temos o predomínio da irracionalidade e do furor típicos da paixão, convertendo a casa-grande e sua patriarcal família em um cenário de rivalidades e desejos. Não devemos, contudo, supor que a posição de Gilberto possa ser inteiramente resumida a esse elogio do excesso. Ao contrário, é perfeitamente possível encontrarmos, também em sua reflexão argumentos de índole nitidamente racional, argumentos capazes até de propor explicações alternativas, e conduzidas de forma impecavelmente ponderada e sociológica, a este privilégio da hybris como causa daquela confraternização (Araújo, I994: 59). ${ }^{16}$ 
O encaminhamento dado ao livro mostra como as noções instrumentalizadas por Freyre conferem significado original à expressão antagonismos em equilíbrio. ${ }^{17}$ Por que original? Nos autores que lhe teriam inspirado a expressão, a conotação se aplicaria à conciliação política, ao equilíbrio entre ciência e religião, à razão diante da experiência, características da sociedade inglesa. A particularidade de Freyre no emprego dessa expressão diz respeito à interpretação que faz das categorias com enquadramentos diferentes, direcionados às situações concretas vivenciadas no período colonial, sempre referidas à aceitação de assimetria presente nas relações sociais - se na Inglaterra a conciliação se dava entre homens livres, no Brasil as relações eram de dependência e submissão: entre proprietários e escravos, entre portugueses e colonos nativos.

Sobre essas relações sociais Benzaquen aponta situações diversas: o louvor aos franciscanos atentos à natureza, às artes manuais diante dos jesuítas altamente intelectualizados; a convivência do catolicismo com ritos de origem africana, envolvendo práticas mágicas; o sadismo dos senhores e o masoquismo dos escravos; a linguagem autoritária daqueles frente à doçura submissa tanto destes como das mulheres e meninos; o público e o privado. Gilberto as apresenta como divergências que podem perfeitamente conviver.

O livro aborda ainda obras publicadas por Freyre nos anos I930, em especial Sobrados e mucambos (I936) e Nordeste, bem como alguns artigos de jornais. Benzaquen aponta várias mudanças que esses textos introduzem em pontos expostos em Casa-grande \& senzala. Principalmente no primeiro é ressaltada a decadência do patriarcado em função das mudanças modernizadoras provocadas pela vinda da corte portuguesa para o Rio de Janeiro, pela urbanização, pela "deserção" dos jovens de engenho tornando-se bacharéis, entre outras. Apesar de Gilberto Freyre reconhecer essas mudanças, chama atenção também para a persistência de muitos traços da tradição colonial. Lembra, ainda, as novas formas pelas quais esses antagonismos ganham equilíbrio, persistindo na política os arranjos nos velhos moldes autoritários.

Ao final de Guerra e paz, fechando sua argumentação, numa passagem de grande beleza Benzaquen (I994: 207-208) lembra que o autor de Casa-grande \& senzala apresenta

duas formas diversas de equilibrar antagonismos: uma, mais "feminina", temperada e medida, mostra-se capaz de produzir uma harmonia absolutamente estável entre distintas heranças culturais; a outra, mais "masculina", eminentemente ambígua, instável e paradoxal, parece se radicar na excessiva experiência colonial, mas ganha uma sobrevida na própria forma de Gilberto construir sua argumentação.

Volto às primeiras afirmações deste artigo sobre a tendência de Benzaquen a matizar a oposição texto e contexto. Indo além de uma síntese entre opostos, procurei mostrar que na sequência de sua investigação nosso autor procedeu a uma análise da produção integralista de Plínio Salgado articulando os seus contextos histórico e léxico e apoiado em sólida base teórica. Isso permitiu não 
só que construísse uma visão original sobre o integralismo e o papel daquele autor na edificação dessa doutrina, como contribuísse decisivamente para a consolidação de uma metodologia de análise do pensamento social.

Em Guerra e paz: Casa-grande \& senzala e a obra de Gilberto Freyre nos anos 30, persiste a articulação destes mesmos elementos - contexto histórico, contexto léxico e suporte teórico. O caminho trilhado, no entanto, é muito diferente. A conjuntura histórica marcada pelos acontecimentos de I930 e seu desdobramento não predispuseram Gilberto a discutir diretamente a situação políticosocial, como o fizeram os autores integralistas. Benzaquem mostra que, discordando das propostas modernizadoras contidas no modernismo paulista, ele se abre para outra vertente, que vê a sociedade marcada pela tensão e pela ambiguidade, tanto por sua aproximação à literatura de vanguarda de sua época como às então versões contemporâneas da sociologia que retomavam aspectos do pensamento de Durkheim valorizando a transgressão e o excesso. As preocupações de Freyre, portanto, se inseriam em contexto histórico em que as propostas modernizadoras ganhavam corpo, e as polêmicas sobre o caráter ou a identidade da sociedade entravam na discussão pela negação da homogeneidade, crise que abria espaço para novas formulações na área das ciências sociais.

Apontei, ainda, que no estudo sobre o integralismo, Benzaquen nega partir de ideias preconcebidas comuns na bibliografia que interpreta o líder da Ação Integralista Brasileira. Busca apreender a lógica do pensamento de Plínio Salgado com base na derivação entre as diversas categorias utilizadas por ess e autor, concebidas como instrumentos de pensamento. Em Guerra e paz a relação entre os conceitos ou as noções que apoiam a argumentação não resulta daquela derivação ancorada nas chaves da história. Não se trata de derivação, consequência de um esquema de pensamento, mas de criação singular operada a partir de diálogo crítico com as formulações antecedentes. Persiste a já apontada atitude de respeito, uma vez que Ricardo busca "por dentro" o entendimento do pensamento do autor estudado.

À segunda edição de Guerra e paz: Casa-grande \& senzala e a obra de Gilberto Freyre nos anos 30, publicada em 2005, Benzaquen acrescenta a nota:

Esta nova edição reproduz basicamente a anterior, corrigindo apenas alguns equívocos gramaticais e de estilo. Contudo, vale a pena ressaltar que isto ocorre inclusive, porque, nestes últimos onze anos, houve um significativo aumento tanto do número quanto da qualidade das pesquisas dedicadas ao exame da obra de Gilberto Freyre, pesquisas cuja efetiva avaliação venha a exigir, senão uma revisão da interpretação aqui avançada, ao menos o seu aprofundamento e ampliação.

Elegante, modesto, generoso, este é o Ricardo que conhecemos e amamos. E sabemos que seu livro sempre será uma referência das mais importantes para a análise da obra de Gilberto Freyre. 
ARTIGO | ELIDE RUGAI BASTOS

Elide Rugai Bastos é professora titular do Departamento de Sociologia da Universidade Estadual de Campinas (Unicamp) e pesquisadora do Conselho Nacional de Desenvolvimento Científico e Tecnológico (CNPq). É autora dos livros Gilberto Freyre e o pensamento hispânico (2003) e As criaturas de Prometeu: Gilberto Freyre e a formação da sociedade brasileira (2006). 


\section{NOTAS}

I Agradeço a André Botelho a leitura cuidadosa e as sugestões, incluída a do título inspirado em nosso amigo e grande intelectual Arcadio Diaz Quiñones.

2 Tive oportunidade de referir-me a esses estudos em Bastos (2003).

3 Benzaquen indica a utilização do termo "categorias" como instrumentos de pensamento de acordo com os princípios apontados por Durkheim em As formas elementares da vida religiosa (Araújo, I978: I6I).

4 Explica as razões de não realizar um balanço crítico dessa bibliografia, embora abra essa possibilidade comparativa. "A primeira deriva de um instintivo horror às polêmicas acadêmicas, embora, como é normal e saudável, volta e meia termine por me encontrar no meio delas. A segunda, de cunho menos pessoal, liga-se ao fato de que não me parece razoável esboçar nenhuma análise da literatura produzida sobre o integralismo sem um cuidadoso exame do quadro teórico que presidiu a sua realização" (Araújo, I988a: I8). Embora de fundamento distinto, as duas razões alegadas dizem muito sobre o perfil pessoal e intelectual de Ricardo Benzaquen de Araújo, que sempre se colocou na "República das Letras" (expressão que toma de Gerard Lebrun para acentuar esse traço) respeitosamente em relação às posições teórico-metodológicas que diferiam das suas.

5 Benzaquen informa que em I935 O partido apresenta I.I23 grupos organizados em 538 municípios e abriga $400 \mathrm{mil}$ adeptos, distribuídos de norte a sul do país.

6 Sobre a abordagem marxista do período lembro o livro de Caio Prado Jr. (1933) Evolução política do Brasil, publicado no mesmo período.

7 Sapere audem aparece no texto de Horácio Epistularum liber primus, mas a utilização mais corrente da expressão "ousar saber" decorre do convite de Kant aos leitores de O que é o esclarecimento e, ainda, de Crítica da razão pura.

8 A indicação de tratar-se de contextos definidos como diversos é minha, mas está presente na argumentação de Benzaquen, embora não rotulados como contexto histórico ou contexto léxico. 
9 Assinalo que Benzaquen refere-se ao jurista Walter Burckhardt, citado por Reale (I968) em Teoria tridimensional do direito, apoiando-se na formulação desse autor sobre reforma moral. Acredito que vale o esclarecimento para que não se confunda Walter com o historiador Jacob Burckhardt, dos conhecidos textos A civilização do Renascimento na Itália e Reflexões sobre a história.

Io "Para o historiador dos tempos modernos é especialmente importante ter cuidado com as opiniões geralmente aceitas que dizem explicar tendências históricas porque durante o último século foram elaboradas numerosas ideologias que pretendem ser as 'chaves da história', embora não passem de desesperados esforços de fugir à responsabilidade" (Arendt, 20I2: 28).

I I A análise comparativa das morfologias do pensamento conservador e do pensamento liberal pode ser consultada em Mannheim (I959) ou ainda em Bendix (I964 e I967), Lukes (1973), Nisbet (I986).

I2 Benzaquen lembra que Plínio Salgado não desenvolve argumentação voltada para a construção do Estado. No quadro do integralismo quem apresenta essa abordagem é Miguel Reale.

I3 Benzaquen mostra que Gilberto Freyre trabalha com uma definição neolamarckiana de raça, explicitando as bases dessa adesão, que o leva a aproximar-se, em Columbia, mais do sociólogo Franklin Giddings do que do antropólogo Franz Boas.

I4 Essa característica de convencimento e afirmativa sem contestação aparece em vários pontos de Casa-grande \& senzala. Cito, como ilustração, o primeiro parágrafo do IV capítulo: "Todo brasileiro, mesmo o alvo, de cabelo louro, traz na alma, quando não na alma e no corpo - há muita gente de jenipapo pelo Brasil - a sombra, ou a pinta, do negro" (Freyre, I933: 303). Vale observar que em edições posteriores, a frase aparece modificada, incluindo o indígena na argumentação.

I5 Casa-grande e senzala é o primeiro volume de uma série de três livros - Sobrados e mucambos (1936) e Ordem e Progresso (I959) - que Gilberto Freyre denominará Introdução à História da Sociedade Patriarcal no Brasil, dedicados a discutir 
as transformações da sociedade brasileira no período compreendido entre a colônia e a Primeira República. O livro Nordeste (1937) também aborda a temática da mudança social e de seus efeitos.

I6 Benzaquen emprega o termo grego hybris no sentido de transformações físicas e geográficas em culturais.

I7 Sobre a expressão antagonismo em equilíbrio Maria Lucia Garcia Pallares-Burke (2005: 4I) afirma: Tendo Gilberto Freyre a "tomado originalmente de intelectuais ingleses, nesse caso Thomas Carlyle e Herbert Spencer - e reforçado pelo norte-americano Giddings - esse conceito foi transferido para novos contextos a fim de interpretar o Brasil".

\section{REFERÊNCIAS BIBLIOGRÁFICAS}

Araújo, Ricardo Benzaquen de. (I994). Guerra e paz: Casagrande \& senzala e a obra de Gilberto Freyre nos anos 30. Rio de Janeiro: Ed. 34.

Araújo, Ricardo Benzaquen de. (I988a). Totalitarismo e revolução: o integralismo de Plínio Salgado. Rio de Janeiro: Zahar.

Araújo, Ricardo Benzaquen de. (1988b). In medio virtus: uma análise da obra integralista de Miguel Reale. Rio de Janeiro: CPDOC/FGV.

Araújo, Ricardo Benzaquen de. (1978). As classificações de Plínio: uma análise do pensamento de Plínio Salgado entre I932 e I938. Revista de Ciência Política, 2I/3, p. I6I-I80.

Arendt, Hannah. (2012). As origens do totalitarismo. Tradução de Roberto Raposo. São Paulo: Companhia das Letras.

Aron, Raymond. (1967). Les étapes de la pensée sociologique. Paris: Gallimard.

Bastos, Elide Rugai. (2003). O CPDOC e o pensamento social brasileiro. In: Camargo, Célia et al. (org.). CPDOC 30 anos. Rio de Janeiro: Ed. FGV, p. 97-II9.

Bendix, Reinhard. (1967). Tradition and modernity reconsidered. Comparative Studies in Society and History, 9/3, p. 292-346.

Bendix, Reinhard. (1964). Nation-building \& citizenship: studies of our changing social order. New York: John Wiley and Sons. 
Botelho, André \& Schwarcz, Lilia Moritz. (20I I). Simpósio: Cinco questões sobre o Pensamento Social Brasileiro. Lua Nova, 82, p. I39-I59.

Durkheim, Émile. (I996) [I9I2]. As formas elementares da vida religiosa: o sistema totêmico na Austrália. Tradução de Paulo Neves. São Paulo: Martins Fontes.

Falcon, Francisco. (I988a). Prefácio. In: Araújo, Ricardo Benzaquen de. Totalitarismo e revolução: o integralismo de Plínio Salgado. Rio de Janeiro: Zahar, p. II-I6.

Freyre, Gilberto. (1933). Casa-grande \& senzala. Rio de Janeiro: Maia e Schmidt Ltda.

Lamounier, Bolivar. (I977). Formação de um pensamento político autoritário na Primeira República: uma interpretação. In: Fausto, Boris. O Brasil republicano, 2 (História Geral da Civilização Brasileira, 9). Rio de Janeiro: Difel, p. 343-374. Lukes, Steven. (1973). Individualism. New York: Harper \& Row. Mannheim, Karl. (1959). Conservative thought. In: Essays on sociology and social psychology. London: Routledge and Kegan Paul, p. 74-II9.

Nisbet, Robert. (1986). Conservatism: dream and reality. New Jersey: Transaction Publishers.

Nisbet, Robert. (I966). The sociological tradition. New York: Basic Books.

Oliveira, Lúcia Lippi; Gomes, Eduardo Rodrigues \& Whately, Maria Celina.(I980). Elite intelectual e debate político nos anos 30: uma bibliografia comentada da Revolução de I930. Rio de Janeiro/Brasília: Ed. FGV/Instituto Nacional do Livro.

Pallares-Burke, Maria Lúcia Garcia. 2005. Gilberto Freyre. Um vitoriano dos trópicos. São Paulo: Ed. Unesp,

Prado Jr., Caio. (I933). Evolução política do Brasil. São Paulo: Brasiliense.

Reale, Miguel. (1994) [1968]. Teoria tridimensional do direito. 5 ed. São Paulo: Saraiva.

Salgado, Plínio. (1935). Psychologia da revolução. Rio de Janeiro: José Olympio.

Salgado, Plínio. (1933). O que é o integralismo. Rio de Janeiro: Schmidt. 


\section{SOBRE OS PRINCÍPIOS: RICARDO BENZAQUEN E OPENSAMENTO SOCIAL}

Resumo

O objetivo do artigo é apontar a contribuição de Ricardo Benzaquen para o pensamento social por meio do estudo de seus métodos de análise. Optou-se por examinar, em particular, seus escritos sobre integralismo produzidos entre os anos I970 e I980 e o livro Guerra e paz: Casa-grande \& senzala e a obra de Gilberto Freyre nos anos 30, publicado em I994. São indicados pressupostos teóricos e encaminhamentos analíticos que balizam o trabalho do autor, e demonstra-se a consistente contribuição de Benzaquen à consolidação da área de pensamento social retomando o caminho trilhado por ele na definição de um método de análise que enriquece o conjunto de instrumentos disponíveis à reflexão dessa área.

\section{ON PRINCIPLES: RICARDO BENZAQUEM AND SOCIAL THOUGHT}

Abstract

This article aims to highlight Ricardo Benzaquen's contributions to social thought through a study of his analytical methods. It focuses mostly on his writings on integralism produced during the I970s and I 980 s and on the book Guerra e paz: Casa-grande \& senzala e a obra de Gilberto Freyre nos anos 30 [War and Peace: The Masters and the Slaves and the Work of Gilberto Freyre in the I930s], published in I994. The article draws attention to the theoretical pressupositions and analytical procedures that frame the author's work, constituting Benzaquen's enduring contribution to the consolidation of the field of social thought. It thus resumes the avenues he pursued in defining a method of analysis that enriches the set of instruments available for reflection in this field.
Palavras-chave

Ricardo Benzaquen de Araújo;

Plínio Salgado;

Gilberto Freyre;

pensamento social;

questão racial.

\section{Keywords}

Ricardo Benzaquen de Araújo;

Plínio Salgado;

Gilberto Freyre;

social thought;

race issue. 